Lotres, Lima, Univ. San Marcos. 63 (91): 19-27, 1992.

\title{
Un examen del "Esse Est Percipi" berkeleyano
}

ARSENIO GUZMAN JORQUERA

1. La afirmación berkeleyana de que ser es ser percibido constituye un difícil problema para todo aquel que suponga que el conocimiento ha de ser objetivo, en el sentido de que el contenido de nuestra experiencia debe ser comparable con una realidad exterior. Consideramos que la tesis de Berkeley es errónea, y nuestro propósito, en el presente trabajo, es refutarla.

Entendemos que refutar signifíca destruir las razones del contrario; consecuentemente, juzgamos incorrecto el proceder, como habitualmente se hace, a oponer a la tesis que se discute oira tesis cualquiera, pues en tal coso quedan intactos la tesis del adversario y no se habrá avanzado nada en su refutación; salvo, claro está, que estuvievagabsolutän eñteoprobactoo la corrección de la tesis que se opone, deduciéndose de ello, de ser del caso, la imposibilidad de la primera. Mas si la tesis opuesta es también una de principio, la cuestión de su corrección absoluta estará más allá de toda posible prueba.

No opondremos, entonces, a la llamada concepción "idealista" de Berkeley, una posición "realista" (cosa demasiado frecuentemente hecha) (1), por cuanto tal proceder es metódicamente inadecuado y filosóficamente insuficiente, por más que a alguien le quede interiormente la tranquilizadora sensación de estar en lo cierto.

(1) Esta es la actitud presente en autores tan diversos, para algunos ejemplos, como: Alfred J. Ayer, The Foundations of Empirical ISnowledge, The MacMillan \& Co. Ltd., London, 1955, pp. 65 ss. Mario Bunge, Epistemologia Editorial Ariel, Barcelona, i981, pp. 140 ss. Margarita Valdez, Sentidos del término "conciencia" y teoría de la iủentidad, en La conciencia: el problema mente cerebro, Augusto FernándezGuardiola editor, Editorial Trillas, México, 1979, p. 29. 
Intentaremos mostrar en lo que sigue que las afirmaciones de Berkeley, sin salimos de su contexto, son insostenibles.

2. Para los fines que perseguimos (2), señalaremos algunas de las ideas centrales de nuestro autor.

Berkeles afirma: 1) "Es evidente para quienquiera que haga un examen de los objetos del conocimiento humano que éstos son: o ideas impresas realmente en los sentidos, o bien percibidas mediante atención a las pasiones y las operaciones de la mente; o, finalmente, ideas formadas con ayuda de la imaginación y de la memoria" (3).

Admite cisimismo, que: 2) 'Existe algo que conoce las ideas llámese mente, alma, espíritu, yo (4).

Agrega luego a afirmación: 3) Ni nuestros pensamientos, ni pasiones, ni las ideas pueden existir sin la mente que los perciba. $\mathrm{Su}$ existir consiste en que se los perciba (5).

Lo que sigue en el texto es, en general, una sucesión de argumentos, objeciones que el autor piensa que le pueden ser opuestas y las respuestas a las mismas.

3. Nuestro propósito qquí es dejar en claro que los argumentos fundamentales que Berkeley invoca en su favor incurren, en lo esencial, en Petición de Principio. Veamos esto con más detenimiento.

a) Cuando sostiene que la opinión que considera que los objetos sensibles tienen una existencia real, distinta de la de ser percibidos, impliefiunce contradicción ress de advertir que tal contradicción (6) ocurre porque por hipótesis, según las afirmaciones 1), 2) y 3y, solo hál 1deas, y la existencia de los objetos consiste en ser percibidos. Lo incorrecto de la argumentación estriba en que esta contradicción (conclusión del argumento) quiere tomarse como prueba de la patente verdad de las tesis del autor (y del error del contrario) (7); pero la verdad atribuida a la conclusión del argumento (llegamos verdaderamente a una contradicción) sólo sería tal si previamente hubiéramos probado la verdad de las premisas (1), (2) y (3). Si todo el ar-

(2) El presente trabajo no pretende ser una exposición del pensamiento de Berkeley.

(3) Georges Berkeley, A Treatise Concerning the Principles of Human Knowledge .... The Open Court Publishing Co., Chicago, 1903. (Principios del conocimiento humano, Aguilar S. A., Buenos Aires, 1962) sec I.
(4) Cf. Ibid. II.
(5) Cf. Ibid. III.
(6) Cf. Ibid. IV-V.
(7) Cf. Ibid. V-VI. 
gumento pretende ser una demostración, entonces éste constituye una evidente pelición de principio (si no pretendiera ser una demostración. sería nada más un juego lógico; fácticamente vacío y totalmente irrelevante).

b) De la misma naturaleza y error son los argumentos según los cuales la noción filosófica de materia implica contradicción (8), o el relativo a la "substancia material" (9).

C) Igualmente, el argumento relacionado con la negacion de la existencia absoluta de cosas no pensantes constituye petición de principio (10), con el agregado de que la no aceptación está ligada a la suposición de que debe ser así, pues no podemos llegar a conocer eso (11); esto último es un típico argumento por la ignorancia.

d) Las restantes consideraciones en la obra repiten, en lo central, y cuando es pertinente, lo arriba señalado. No será, por tanto, necesario detenernos más en este punio.

4. Descariado el aparente apoyo lógico, la posición del auior queda reducida a un grupo de afirmaciones de las que puede pensarse igualmente que son verdaderas o que son falsas. Y si bien con lo expuesto podría justificadamente decirse que se ha anulado el soporte de la concepción del autor, consideramos conveniente proceder al examen de las afirmaciones en referencia, pues cabe la posibilidad de que ellas nos conduzcan a situaciones en las que se hagd patente la imposibilidad de su defensa.

La afirmación 2), es una con la que estaremos plenamente de acuerdo; con la advertencia, como es de suponer, de que de ella no se sigue la mo Dexistendial absoluat delsotros objetos. No viene al caso entoncelso intentar cuestiongrlaerPor lo demás, es de suponer que nadie la pondría seriamente en duda (si alguien lo hicierc, podríamos responder apropiadamente; pero no nos ocuparemos ahora de este punto). La daremos entonces por cierta.

Si con 3) y 1), supuesto 2), negamos la existencia absoluta de cosas no pensantes, consideramos que hay por lo menos una objeción grave que puede oponerse a semejante negación. Procederemos a examinarla en detalle.

Moviéndonos dentro del ámbito de nuesiras percepciones, podemos plantear un argumento basado en la idea de que algunas percepciones pueden ser falsas, idea que proviene del reconocimiento de la incompatibilidad entre ciertas percepciones. Adviértase, $\sin$ embargo, que no estamos presuponiendo que haya percepciones falsas (o que tal sea el caso de sus apuestas); estamos

(8) Cf. Ibid. IX

(9) Cf. Ibid. XVIT.

(10) Cf. Ibid. XXIV.

(11) Cf. Ibid. XVIII-XIX-XX-XXI-XXII. 
sencillamente señalando un aspecto de la conclusión de argumento para caracterizarlo. Nos encontramos, entonces, protegidos, en principio, contra el círculo vícioso.

Supongamos que dos personas, inicialmente juntas, comienzan a separarse. Cada una vería a la oira empequeñecerse $\alpha$ medida que se aleja. Llamemos $\mathrm{A}$ y $\mathrm{B}$ a estas personas.

Desde la perspectiva de $A, B$ se empequeñece a medida que se aleja, mientras que $A$ misma conserva sus dimensiones. Un observador $\mathrm{C}$ colocado junto a A confirmaría esta perceptible situación.

Desde la perspectiva de $B, A$ se empequeñece a medida que se aleja, conservando B sus dimensiones; como en el caso anterior, un observador D confirmaría su apreciación.

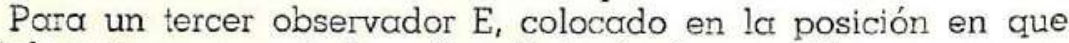
inicialmente se encontraban $A$ y $B$, tanto $A$ como $B$ se empequeñecerían; conservando por lo demás él mismo sus dimensiones.

Finalmente, para su cuarto observador F, colocado a cierta distancia de A y B, de modo tal que al alejarse éstos entre sí no incrementen notoriamente su distancia respecio de él, $\AA$ y $B$ conservarían sus tamaños aparentes.

(Como es de imaginar, los/observadoes pueden multiplicarse indefinidamente, pero los mencionados son suficientes para los efectos del razonamiento).

En las situacioses señaladas, tendríamos varias percepciones diferentes y simultámeas, en lo que cabe, referentes al mismo objeto. Estas son inconciliables entre sí, al punto de no poder ser sostenidas al mismo tiempo sin incurrir en contradicción: por ejemplo, A no puede sep grande bbjelivamente (según C) y pequeño objetivamente (sejúng Blaubdiadai vezinnorpuede tener dos tamaños al mismo tiempo y, además, no tenerlos (según el informe de $\mathrm{F}$

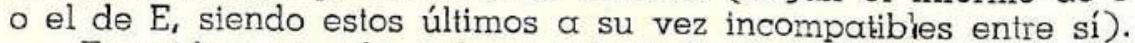

Es evidente que los informes de A, B, C, D, E y F están igualmente basados en la percepción; es más, no hay objetivamente manera de decidir respecto de las dimensiones de A y B. Semejante situación es incorregible.

Ahora bien, si ser es ser percibido dtenemos esta multitud de seres? ¿Son todos ellos efectivos? La respuesta sólo puede ser no, en vista de que, de no serlo, las afirmaciones relativas al darse de tales seres nos conducirían a patentes contradicciones.

Ciertamente, contra lo que decimos, podría afirmarse que ser es ser percibido en el más absoluto sentido de los términos, de modo que todo lo percibido es sin más; y sin que por ello hayan de surgir contradicciones como las mencionadas , pues éstas solo se le presentarian como tales a quien fuese partícipe de un realismo encub'erto, en el cual se le figurase que lo percibido lo es en relacion con algo real respecto de lo cual resultase verdadero o 
faso. Assí, nuestro ejemplo relativo a personas que se alejan y observadores pasaría a ser considerado como una muestra de este error, pues se diria que las personas de que hablamos, es decir, las que son objeto de percepciones diversas en el argumento, tienen una existencia real presupuesta, independiente de su ser percibidas, ya que de otro modo no podría afirmarse que se tienen percepciones diferentes de un mismo objeto, que no todas pueden ser verdaderas y las demás consecuencias señaladas. Āsí, bajo esta radical perspectiva, en rigor lo percibido parecería estar más allá de calificativos tales como verdadero o falso. Por tanto, quien sobre la base propuesta prelendiera afirmar que seres algo más que ser percibido, estaría cometiendo petición de principio, puesto que estaría dando, previamente, por verdadero que ser es algo más que ser percibido, es decir, sosteniendo un reaitismo.

No obstante, consideramos que la objeción señalada no es procedente, dado que las contradicciones planteadas no están furidadas en el hecho de que algunas percepciones sean verdaderas - falsas, como cosa probada, en función de una realidad con la cual hayan sido comparadas; ni siquiera estám basadas en la posibilidad de semejanle comparación, posibilidad que obviamente supondría un realismo.

Lo que está en juego es más bien el hecho de que las percepciones mismas (en el ejemplo propuesto) son incompatibles y no pueden ser al mismo tiempo sostenidas; y si una cuailquiera es afirmada, entonces otra, u otras, serán consecuentemente negadas, y viceversa. Es respecto dó esto que puede decirse que unas percepciones son verdaderas y otras falsas. Por supuesto, cabe la posibilidad de reohazarotodce las pecepeiones, $y$ en una situación así no se diríg que ung epercepción es verdedera; pero esto constituiría un prob.ema enteramenie diferente, como posteriormente ve:emos; dejémoslo, entonces, para ulteriores consideraciones. Pero téngase presente, por el momento, que ni aun el rechazo de todas ellas eliminaría la incompatibilidad de las mismas.

En definitiva, no es procedente la objeción señalada, y no se ha cometido petición de principio en nuestro argumento.

Por otra parte, es posible formular una variante de la abjeción anterior afirmando que el argumento no puede ser construido, dado que en principio las percepciones que se mencionan son de diferentes sujetos, no habiendo, por tanto, razón para suponer que ellas tengan que ser compatibles o que puedan no serlo. Se diría entonces que sólo si se tratara del mismo sujeto, y si este tuviera percepciones simultáneas incompatibles, el argumento sería admisible.

En respuesta, cabe señalar que si de meras percepciones se tratara, la objeción podría ser efectiva; pero como lo cue se discute es la tesis de que ser es ser percibido, la observación se tor- 
na inoperante. Habida cuenta de la identidad entre ser y ser percibido, sostenida en la referida tesis, se entiende que la cuestión deja de ser la relativa a las percepciones para convertirse en la relativa al ser adherido a ellas y la de cómo podrían ser éec. tivos seres mutuamente incompatibles; y es bien claro que la incompatibilidad de estos últimos no radica en la accidental circosstancia de darse en uno o en varios sujetos.

Naturalmente, si se sostiene que las percepciones de diferentes personas son diferentes seres, no habrá razón alguna para considerar que éstos son incompatibles; mas esia no incompatibilidad se habrá obtenido al precio de encontrarnos ahota ante una infinidad de seres que de ninguna manera pueden quedar articulados dentro de lo que entendemos cuando hablamos de objetos. Se perdería toda posib!e noción relativa a la unidad del objeto; y no nos referimos a un presunto objeto exterior, pues ésle está negado desde el punto de partida, sino a los objetos como lo percibido. Ocurre que si cada cual tiene sus percepciones y sus objetos (seres), no tendría sentido hablar de un objeto, pues éste no sería tal, salvo que lo pensáramos como siendo una infinidad de distintos seres y ninguno de ellos en rigor, pues el objeto de mi percepción no es el de las de otros. No habría siquiera acuerdo acerca de qué es un objeto, en el sentido corriente del término.

La única salida razonable en esta situación sería el solipsismo, caso en el que desaparece el problema de los otros y sus percepciones. Pero esie extremo va en contra de la afirmación (2) de Berkeley. Contradice igualmente la afirmación berkeleyana de que todos los objelos son percibidos por Dios, de modo que existen aunque ninguno de posotros los percibor (12). Pero, por oiro lado, si Dios fuera el unico yo, en una suerte de solipsismo divino, la consecuencia sería no sólo la no existencia de las percepciones de los otros, sino la no existencia de sus conciencias mismas, lo que evidentemente no es el caso.

Por lo demás, si yendo más allá de lo proyectado por Berkeley, alguien asumiera que hay un solo yo, el suyo propio, y sus contenidos de conciencia, éste tendría dentro de sí todas las contradicciones imaginables (en los términos en que veníamos considerando el punto), y a la larga su posición sería víctima de sus consecuencias. Y de nada le serviría ir introduciendo dentro del círculo de su conciencia todas las reglas, hipótesis, teorías, o lo que fuere oportuno, para hacer de éste un sistema coherente. Pues, por una parte, todo lo conocido, dejando "fuera" lo mucho que no le es conocido, sería insuficiente para dar cuenter de todos los contenidos de su conciencia. Por otro lado, la mayor parte de

(12) Cf. Ibid. VI. 
lo que llamamos conocido, le sería muy indirectamente conocido, dado que no está al comienzo en su conciencia y aparece en ella sólo en relación con lo que otros dicen, otros que están por principio negados; así, ese conocer suyo consistiría meramente en el poder repetir términos o expresiones acerca de cuyos significados - alcances tendría en su conciencia sólo un absoluto vacío, que de poco le serviría para dar razón de todos los contenidos de su conciencia. Tocio lo expuesto nos muestra lo incongruente de su posición. Aun si el solipsista incluyera todo dentro del círculo de su conciencia, es decir, tanto lo conocido como lo que no lo es, las dificultades señaladas no se eliminarían. Por lo demás, ya no diríamos de él que era un solipsista, sino que era alguien que creía ser el mundo.

En suma, si llegamos al extremo solipsista, todas las incompatibilidades se darían en el sujeto único, y el problema no se resuelve por esta vía. Si alguien no hubiera quedado satisfecho con lo expuesto acerca de las incompalibilidades en las percepciones de un sujeto, podría proponérsele el ejemplo siguiente: supóngase el caso de una persona mirando su mano y el reflejo de loa misma en un espejo. Sin embargo, pensamos que no son necesarias estas ilustraciones.

Después del largo comentario anterior, queda en claro que si hay percepciones incompatibles, no es posib!e sostener que ser es ser percibido. Si de una percepción se dijera que es verdadera, debiera decirse que las que sean incompatibles con ella son falsas $\mathrm{y}$ viceversa. Pero no tiene ninguna relevancia para nuestra argumentación, ni se le opone, la suposición de que todas las percepciones podrian serlalsastóesto que Qún $\$$ Sella fuese una posición correcta, no haría sino confinmar nuestra tesis de que ser es algo más que ser percibido. En todo caso, el que todas las percepciones puedan ser falsas, o que lo sean, es algo que no necesitamos discutir ahora, nos basta con lo señalado, y no nos detendremos en más consideraciones en torno a tan extremosa posición.

Como consecuencia de todo lo anterior, puede sostenerse que hay algo que es percibido, pero no es; a no ser que se admitiera que hay un falso ser, vale decir, un ser que no es, con todo lo absurdo que esto implica. Eso, naturalmente, es indefendible.

Por supuesto, puede afirmarse que en cuanto percibido ese ser es, pero no es objetivamente; pero lamentablemente esta simp.e afirmación no proporciona una respuesta adecuada, pues implica presuponer una realidad exterior respecto de la cual puede una percepción ser objeliva o no serlo, y tal presupuesto echaría por tierra las cafirmaciones 1) y 3 ).

Pero este último argumento puede afinarse $\mathrm{y}$ tomar un aspecto más sólido, sosteniendo que la reflexión es capaz de mos- 
trarnos, por deducciones, inducciones, o lo que fuese, que el cambio o la diferencia en las dimensiones (en nuesiro argumento) es aparente, y puede saberse acerca de la genuina dimensión de los objetos aplicando, por ejemplo, leyes de perspeciiva. Esto parece ofrecer una ingeniosa salida a la objeción que planteamos. Pero ocurre que esta respuesia es igualmente improce. dente por cuanto:

a) Presupone una existencia "absoiuta" de los objelos, respecto de la cual algunas percepciones resultarían ser sólo apariencias; es decir, ser es algo, más que ser percibido, to que significa admitir un realismo, que es justamente lo que se quiere negar; o, en el caso de que el realismo no quiera cidmitirse (como en el caso de Berkeley), obliga a reducir bo real a las percepciones de Dios, con lo que la situación no se corrige en absoluto, dado que éstas serían para nosotros tan externas y consistentes como las cosas que llamamos reales y respecto de ellas nuestras percepciones serían apariencias, de manera que definitivamente ser sería algo más que ser percibido; al menos parct nosotros, cuando no para Dios. Āun con Dios y sus percepciones el problema subsiste, como más adelante veremos.

b) Además de lo señalado, cabe destacar que lo que está en juego es el hecho de que al menos algunas percepciones son aparentes, y que cualquier intento de esclarecer su carácter de tales implica la admisión de que lo son y, consecuentemente, la de que ser es a'go más que ser percibido.

Poner a Dios como fundamento último de la realidad de los objetos percibidos, en cuanto éstos son percibidos por él, gene ra también dificultadeslinsuperables. Letras

En primer lugänrsie Dioscènahi Yorquestiene percepciones, debe tenerlas todas, tanto las aparentes como las que no lo son, pues de no ser así, habría algo en nuestro pensamiento de lo que él no lendría conocimiento, lo que contradiría la definición misma de Dios. Ahora bien, si tiene todas las percepciones, todas son igualmente objetivas; $y$, en consecuencia, considerando las contradicciones que señalábamos, habría un ser que no es. Esto es incadmisible.

En segundo lugar, si se alirmara que Dios es un yo con rercepciones desde su perspectiva, intentando así eliminar toda in compatibiliajad que pueda dar lugar a cbservaciones como la chterior, estaría en este respecic tan limitado como nosotros; y esio es también inadmisible, por lo antes dicho, subsistiendo además las dificultades señaladas. Por lo demás, en tal condición, no podría ser el fundamento final propuesto. Cabe agregar aue si se asume que Dios tiene todas las perspectivas, se reproduce el caso indicado en primer lugar.

Finalmente, en tercer lugar, si se pensara que Dios no pue- 
de ser entendido como un yo con perspectivas, estando fuera del alcance de especulaciones de esta especie, entonces estará también más allá de toda consideración posible el poder siquiera pensar en qué sentido es él capaz de tener percepciones. Se estará impidiendo el uso mismo de la palabra percepción y toda argumentación sale sobrando.

5. Adicionalmente, no puede pasarse por alto que la declarada imposibilidad de las ideas generales abstractas se basa, argumentalmente, en un pedido a su vez imposible. Se exige que tales ideas sean abstracias, esto es, absolutamente desprovistas de especificaciones y, al mismo tiempo, que podamos representárnosla o imaginarlas (13). En todo caso, este no es un tema esencial para lo que veníamos discutiendo.

6. Cabe que alguien objete que a lo largo de toda la exposición hemos estado "encerrados" dentro del círculo de la conciencia, quedando de este modo convalidado el argumento de Berkeley. Responderemos que una observación de esta clase sólo sería admisible si previamente se estableciera la verdad de las tesis berkeleyanas, pues de no ser así el objetante estaría incurriendo en petición de principio. Volveríamos, entonces, al comienzo de este escrito; mas en tal circunstancia cuanto deseábamos decir está ya dicho y no será necesario que empecemos ahora a caminar sobre nuestros pasos.

\section{Biblioteca de Letras "Jorge Puccinelli Converso»}

(13) Cf. Ibid. introducción VI-VII-VIII-IX-X. 